\title{
Effects of two desensitization techniques, biofeedback and relaxation, on intractable epilepsy: follow-up study
}

\author{
R. J. CABRAL AND D. F. SCOTT ${ }^{1}$ \\ From the Section of Neurological Sciences, The London Hospital, Whitechapel, London
}

SYNOPSIS Two techniques of desensitization, biofeedback and relaxation, were employed in a crossover design for the treatment of three young female patients suffering from drug resistant epilepsy associated with anxiety and phobic symptoms. The patients were followed up for 15 months after the six months of treatment. The results indicate that both relaxation and biofeedback improved the patients' control of their seizures and the effects were maintained during the follow-up period.

Recently there has been interest in biofeedback techniques for the treatment of patients with epilepsy (Sterman et al., 1974; Kaplan, 1975). The present investigation employs biofeedback and another form of desensitization-namely, relaxation. These two methods were used in a crossover design for the treatment of a small group of patients who had intractable epilepsy associated with anxiety and phobic symptoms. The possible value of these techniques was assessed by both clinical and EEG criteria.

\section{METHOD}

PATIENTS Three young female patients who had attended the London Hospital for at least four years were selected for study. They suffered from resistant seizures in spite of adequate serum levels of anticonvulsant drugs.

Patient 1 was 18 years of age with a long history of petit mal and grand mal. Her tonic/clonic seizures averaged one per month and she had up to 15 'absences' per day on ethosuximide $500 \mathrm{mg}$, phenobarbitone $30 \mathrm{mg}$, and phenytoin $100 \mathrm{mg}$, each given three times a day. Her EEG showed atypical spike and wave discharges as well as localized sharp waves activated by overbreathing. She had anxiety symptoms and social phobias because of her overweight.

Patient 2 was 21 years old and had had petit mal

${ }^{1}$ Address for correspondence: Dr D. F. Scott, The London Hospital, Whitechapel, London E1 1BB.

(Accepted 31 December 1975.) from the age of 6 years, with three major attacks in the three years before this investigation. In spite of 0 ethosuximide $500 \mathrm{mg}$ and phenytoin $100 \mathrm{mg}$, both three times a day, she had 10 to 15 attacks of petit $\stackrel{\mathbb{Q}}{\varrho}$ 음 mal per day. Her EEG showed generalized spike and wave discharges. She was anxious and had fears particularly relating to impending marriage.

Patient 3 was 22 years old. Psychomotor seizures had occurred since 14 years of age. Her attacks averaged three a day, although she took carbamazepine $200 \mathrm{mg}$ and phenytoin $100 \mathrm{mg}$, both three times a day. Hirsutism and other signs of phenytoin intoxication were also present. The EEG showed bitemporal paroxysms which were more marked on the right side. She was anxious and had a variety of social phobias.

APPARATUS The biofeedback instrument used an EEG signal from two silver-silver chloride scalp electrodes, one $2 \mathrm{~cm}$ above the inion and the other at the vertex. The signal was first passed through a frequency-selective filter, tuned to the same frequency as the subject's alpha rhythm. If the selected frequencies exceeded $10 \mathrm{mV}$, peak to peak, they were rectified and fed to a leaky integrator. The integrator output was used to modulate a voltage-controlled oscillator such that the frequency of the oscillator was proportional to both the amplitude and the duration of the rectified activity. The output of the oscillator was 'fed back' to the patient by a loudspeaker.

Routine EEGs lasting 30 minutes and including overbreathing and photic stimulation were obtained in a standard manner using the 10/20 system of 
electrode placement and a 16 channel ElemaSchönander apparatus.

PROCEDURE The six months' treatment period was divided into three months of biofeedback and three months of relaxation. Two patients commenced with biofeedback and proceeded to relaxation; and for the other patient the opposite order was used. These 30-minute treatments were always carried out by R.J.C. and took place on alternate weeks. The patients were taught to relax (Jacobson, 1938) and the degree was gauged by fall in heart rate (Lang et al., 1970). This was measured by ECG written out on one channel of the EEG trace. Patients were then presented with specific anxiety-provoking stimuli (APS) or imagery in a systematic manner (Wolpe, 1958). In the biofeedback sessions, patients learned to produce trains of alpha rhythm with their eyes shut, and the degree of control over alpha activity was quantified by the method of Nowlis and Kamiya (1970). The patients were then presented with APS, as for relaxation. Continuous EEG monitoring was carried out during these sessions.

Between the treatments all patients had routine EEGs, which included five minutes' overbreathing, at three weekly intervals. Subsequently, the tracings were masked, coded, and rated by D.F.S. without knowledge of the patient's clinical state at that time or which course of treatment was being given. The patients rated their state using visual analogue scales (Aitken, 1969) and parents and employers' comments were also obtained. These evaluations were made fortnightly and were scored on a four point scale depending on severity.

After the six months of treatment, the patients were followed up for an average of 15 months. During this period, the patients were assessed clinically at regular intervals and routine EEGs were carried out. These were subsequently rated 'blind' as during the treatment period.

\section{RESULTS}

During biofeedback the amount of alpha activity in the resting state increased on average from 22 to 64 per standard two minute epoch (Table 1). In addition, though the presentation of APS produced a marked decrease in the amount of alpha activity in all subjects, this decrease became less evident towards the end of the treatment period. Relaxation caused an average reduction of heart rate of about $15 \%$, while the presentation of APS caused an increase from the base-line of about $10 \%$ in the first treatment session. In the last session no significant change in heart rate occurred.

Both forms of treatment produced improvement in the EEGs of two patients (nos. 1 and 3, Table 2). For the other patient, relaxation produced no definite change in the resting EEG as compared with the pretreatment level and deterioration was noted in the tracing during hyperventilation. Biofeedback had a more consistent effect in her case. This patient's EEGs carried out during the follow-up period showed only minor fluctuations in the amounts of spike and wave activity during overbreathing. On the other hand, the follow-up tracings of patients 1 and 3 presented a slight increase in abnormality (Table 2).

The patient's assessments of clinical outcome, on visual analogue scales, showed overall amelioration over the whole treatment period (Table 3). This ran in parallel with the remarks of relatives at interviews and in correspondence with employers. Patient 1 became attack-free (score 0 ) and the other two patients presented a steady improvement in their scores, falling from

TABLE 1

AMOUNT (IN SECONDS) OF ALPHA RHYTHM IN A STANDARD TWO-MINUTE EPOCH DURING FIRST AND LAST SESSIONS OF 'BIOFEEDBACK', BEFORE AND AFTER ANXIETY-PROVOKING STIMULI (APS)

\begin{tabular}{|c|c|c|c|c|c|}
\hline & \multirow[t]{2}{*}{ Patients } & \multicolumn{2}{|c|}{ First session } & \multicolumn{2}{|c|}{ Last session } \\
\hline & & Before APS & After $A P S$ & Before APS & After $A P S$ \\
\hline & $\begin{array}{l}1 \\
2 \\
3 \\
\text { Average }\end{array}$ & $\begin{array}{l}25 \\
27 \\
14 \\
22\end{array}$ & $\begin{array}{r}10 \\
10 \\
5 \\
8\end{array}$ & $\begin{array}{r}50 \\
103 \\
40 \\
64\end{array}$ & $\begin{array}{r}45 \\
100 \\
30 \\
58\end{array}$ \\
\hline
\end{tabular}


TABLE 2

EFFECT OF TREATMENT ON EEG

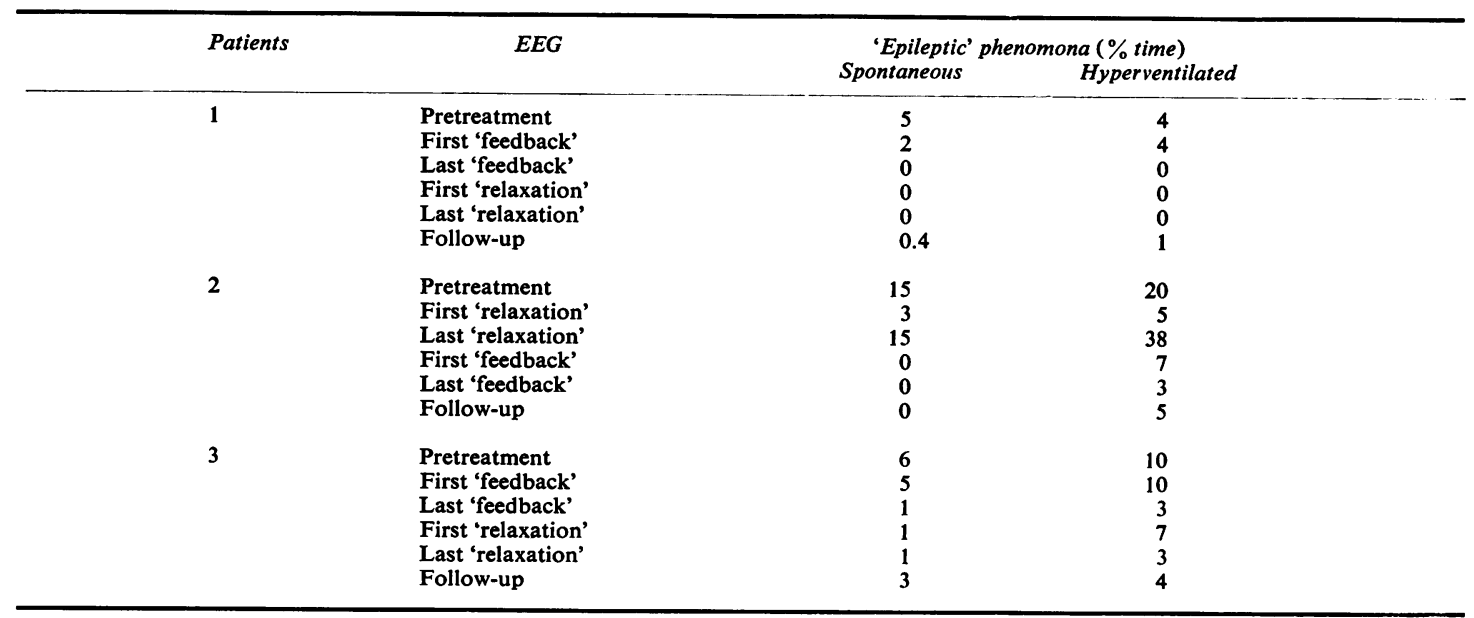

0: nil.

TABLE 3

CLINICAL FEATTURES AND MEAN SCORES BEFORE AND AFTER SIX MONTHS' TREATMENT FOR EPILEPSY

\begin{tabular}{|c|c|c|c|c|c|}
\hline Patients & Before & Mean scores & After & & Mean scores \\
\hline 1 & $\begin{array}{l}15 \text { absences } / \mathrm{d} \\
1 \mathrm{major} \text { attack } / \mathrm{m}\end{array}$ & 3 & $\begin{array}{l}\text { 'Biofeedback' } \\
\text { 'Relaxation' } \\
\text { Follow-up }\end{array}$ & $\begin{array}{l}0 \\
0 \\
2 \text { absences } / \mathrm{w} \\
4 \text { major attacks } / 15 \mathrm{~m}\end{array}$ & $\begin{array}{l}0 \\
0 \\
1.2\end{array}$ \\
\hline 2 & $\begin{array}{l}13 \text { absences } / \mathrm{d} \\
3 \text { major attacks } / 3 \text { yr }\end{array}$ & 3 & $\begin{array}{l}\text { 'Relaxation' } \\
\text { 'Biofeedback' } \\
\text { Follow-up }\end{array}$ & $\begin{array}{l}2 \text { absences } / d \\
3 \text { absences } / w \\
4 \text { absences } / w\end{array}$ & $\begin{array}{l}1.5 \\
0.7 \\
0.8\end{array}$ \\
\hline 3 & 3 minor attacks/d & 3 & $\begin{array}{l}\text { 'Biofeedback' } \\
\text { 'Relaxation' } \\
\text { Follow-up }\end{array}$ & $\begin{array}{l}3 \text { minor attacks/w } \\
2 \text { minor attacks } / w \\
2 \text { minor attacks } / w\end{array}$ & $\begin{array}{l}1.5 \\
0.5 \\
0.5\end{array}$ \\
\hline
\end{tabular}

3 to scores of 0.7 and 0.5 respectively. During the 15 months' follow-up all three patients had some increase in the number of fits, usually at times of stress. These sporadic deteriorations were reflected in their clinical mean scores.

\section{DISCUSSION}

The use of biofeedback techniques in epilepsy (Sterman et al., 1974; Kaplan, 1975) has opened a new avenue to the treatment of drug resistant cases. This method has the advantage of obtaining active participation on the part of the patient as distinct from mere compliance with a drug régime. The approach in the present study was not only to test the efficacy of the biofeedback technique but also that of relaxation, directed at the patient's anxiety and phobic symptoms. All three patients showed a favourable clinical response to both forms of desensitization throughout the treatment period and, perhaps more importantly, this was maintained during the follow-up period. EEG features mirrored the clinical improvement.

The mechanism by which amelioration came about is uncertain. It is possible that anxiety or phobias acted as triggers for seizures, and hence desensitization to these led to improvement. An alternative explanation of the effectiveness of biofeedback could be that the patient's ability to control alpha rhythm would act directly on the epileptic process. However, others (Stroebel and 
Glueck, 1973; Kaplan, 1975) have raised the question of it being a complex placebo.

Another interpretation might be that the results obtained were due merely to the passage of time or other non-specific processes. We consider that these explanations, on their own, are unlikely. However, with the present experimental design they cannot entirely be ruled out.

We are grateful to our patients who kindly cooperated in this study, and also wish to thank Mr D. Maynard for technical assistance with the biofeedback apparatus and Mrs Jean Held for secretarial help.

\section{REFERENCES}

Aitken, R. C. B. (1969). Measurement of feelings using visual analogue scales. Proceedings of Royal Society of Medicine, 62, 898-892.

Jacobson, E. (1938). Progressive Relaxation. University of Chicago Press: Chicago.
Kaplan, B. J. (1975). Biofeedback in epileptics: equivocal relationship of reinforced EEG frequency to seizure reduction. Epilepsia, 16, 477-485.

Lang, P. J., Melamed, B. G., and Hart, J. (1970). A psychological analysis of fear modification using an automated desensitisation procedure. Journal of Abnormal Psycho$\log y, 76,220-234$.

Nowlis, D. P., and Kamiya, J. (1970). The control of electroencephalographic alpha rhythms through auditory feedback and the associated mental activity. Psychophysiology, 6, 476-484.

Sterman, M. B., MacDonald, L. R., and Stone, R. K. (1974). Biofeedback training of the sensori-motor EEG rhythms in man: effects on epilepsy. Epilepsia, 15, $395-416$.

Stroebel, C. F., and Glueck, B. C. (1973). Biofeedback treatment in medicine and psychiatry: an ultimate placebo? In Biofeedback. Edited by L. Birk. Grune and Stratton: New York.

Wolpe, J. (1958). Psychotherapy by Reciprocal Inhibition. Stanford University Press: Stanford. 